\title{
DISCONTINUOUS FOCI AND UNALTERNATIVE SEMANTICS
}

\section{INTRODUCTION: DISCONTINUOUS FOCI}

By the standard question-answer test for focus, we diagnose the VP was arrested by the police to be focussed in (1a). Semantically, the same property should be focussed in (1b), but there is no syntactic constituent that corresponds to the putative focus, which consists of the subject and the verb part of the VP. This is what I call a Discontinuous FOCUS.

(1) What happened to John?

a) John was arrested by the poLICE.

b) The police aRRESted John.

If focus is represented by F-markers in the syntax, there are two principled ways of representing discontinuous foci. Either both parts are F-marked, or a constituent dominating both is. These options are illustrated in (2). Note that option number two requires some additional marking - here ' $G$ ' for 'given' -, so as to make sure that the focus is not realized by an accent on the object John, the default main stress position in a transitive VP.

(2) a) $[\text { the police }]_{\mathrm{F}}[\text { aRRESted }]_{F}$ John

b) [the police aRRESted $\left.\mathrm{John}_{\mathrm{G}}\right]_{F}$

Neither solution seems fully satisfactory, as I will show below. (2a) seems incompatible with the prosodic realization of discontinuous foci, because the subject in these constructions is not realized as one would expect from an F-marked constituent; (2b), on the other hand, is semantically a case of overfocussing: it leads to propositional alternatives, rather than property alternatives, as one would expect.

In this paper I propose a new way of handling discontinuous foci, using UNALTERnative Semantics (UAS, see Büring 2015). In UAS, focus is not syntactically marked; rather, focus alternatives are calculated directly from independently needed structural aspects of the representation, in the case at hand: metrical weights. On this view, (1b) naturally comes out as expressing a property-type focus, analogous to (1a), without committing to individual parts of the structure being focused, or allowing for propositional focus alternatives.

\footnotetext{
* daniel.buring@univie.ac.at
} 


\section{UNALTERNATIVE SEMANTICS}

Like alternative semantics (Rooth 1985, 1992, 1996), UAS systematically maps every syntactic node onto a set of alternatives, i.e., meanings (in the same domain as the node itself) which could be FOCAL TARGETS - for example, the denotation of a previous phrase or utterance with which the sentence containing the focusing is contrasted. Unlike alternative semantics, however, UAS does so by accumulating restrictions on focus alternatives bottom to top. Possible focal targets for a constituent A are then those meanings of the same semantic category as that of A which are not excluded by these restrictions.

\subsection{Basics}

UAS for English utilizes two essential types of restrictions, weak and strong. A WEAK RESTRICTION is imposed on every branching node that shows default metrical relations, which, for English, are characterized in Figure 1. Weak Restriction excludes all alternatives which result from composing an alternative to the weak sister with the literal meaning of the strong sister. Put differently, it excludes all those alternatives that would be allowed had the weak

\begin{tabular}{cc} 
WEAK & STRONG \\
\hline functional & lexical \\
head & complement
\end{tabular}

left projection right projection

Figure 1: Structural metrical defaults, in descending order of importance sister been strong instead.

This is defined in (3a), and abbreviated as in (3b).

\section{(3) WEAK RESTRICTION}

If the relative stress among a node $\alpha$ 's daughters $\mathrm{S}_{\text {strong }}$ and $\mathrm{S}_{\text {weak }}$ accords to the default, $\alpha$ excludes all focal targets in

a) $\left.\left(\operatorname{alt.dom}\left(S_{\text {weak }}\right) \backslash\left\{\llbracket S_{\text {weak }} \rrbracket_{O}\right\}\right) \otimes_{\alpha}\left\{\llbracket \mathrm{S}_{\text {strong }} \rrbracket_{O}\right\}\right)$

b) $x^{\left.\right|_{\text {weak }}} \mathrm{S}_{\text {strong }}$

alt.dom(S) is the ALTERNATIVE DOMAIN of S, which I take to be the set of all meanings in the same domain as the meaning of $\mathrm{S}$ that can be expressed by expressions of the same category as $\mathrm{S} . \otimes_{\alpha}$ stands for the semantic composition rule needed to combine the alternatives of $\alpha$ 's daughters. If, for example, $\alpha$ has daughters $\beta$ and $\gamma$, and the ordinary meaning of $\alpha, \llbracket \alpha \rrbracket_{O}$ is $\llbracket \beta \rrbracket_{O}\left(\llbracket \gamma \rrbracket_{O}\right)$; then alt.dom $(\beta) \otimes_{\alpha}$ alt.dom $(\gamma)$ would be $\{b(g) \mid b \in$ alt.dom $(\beta) \& g \in$ alt.dom $(\gamma)\}$.

Another way of thinking of Weak Restriction is that it says 'if the weak sister is (part of the) focus, so is the strong sister', or: 'the weak sister is not a narrow focus'. The excluded meanings - e.g., those characterized by $(3 a) /(3 b)$ - are generally also written as $\llbracket \alpha \rrbracket_{u}$.

The second type of restriction, Strong Restriction, applies where the metrical weights between two sister nodes have been REVERSED. In this case the restriction requires that the metrically PROMOTED sister be part of a focus. This is formalized in (4). 


\section{4) STRONG RESTRICTION}

If $\alpha$ has undergone prosodic reversal, $\alpha$ excludes all focal targets in alt.dom $(\alpha) \backslash\left(\left(\right.\right.$ alt.dom $\left.\left.\left(S_{\text {strong }}\right) \backslash \llbracket S_{\text {strong }} \rrbracket_{O}\right) \otimes_{\alpha}\left\{\llbracket S_{\text {weak }} \rrbracket_{O}\right\}\right)$

Another way of saying this is 'strong daughter is a focus, weak daughter is not'. It is convenient to characterize the restrictions imposed by Strong Restriction in terms of the alternatives it allows, rather than the excluded ones. This is symbolized as in (5)

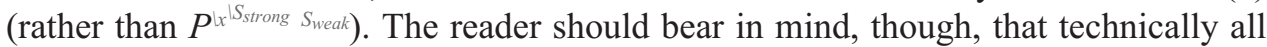
restrictions are in the form of sets of unalternatives, as defined in (4).

(5) $x^{\ \mathrm{~S}_{\text {strong }} \mathrm{S}_{\text {weak }}}$

The workings of Weak and Strong Restriction are illustrated in Figures 2 and 3. In addition to the two restrictions, UAS requires a mechanism of unalternative PROPAGATION. Defined as in (6) - where $\llbracket \mathrm{S} \rrbracket_{u}$ stands for the UnALTERnAtives of S, i.e., the meanings excluded as FTs by Weak and Strong Restriction - Propagation makes sure that (weak or strong) restrictions introduced on lower nodes are propagated all the way up to the root node.

(i)

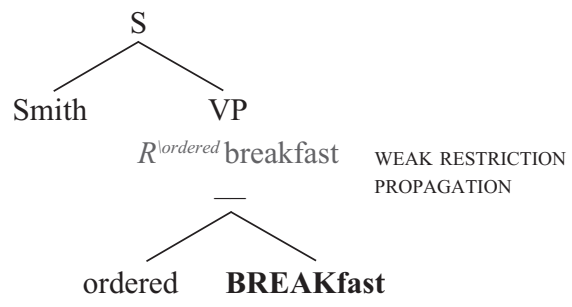

(iii)

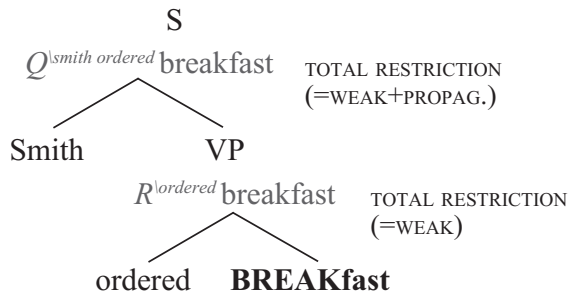

(ii)

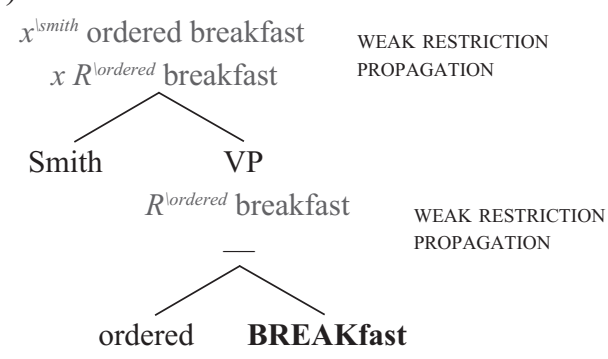

(iv)

$\begin{array}{rrl}\text { S } & \checkmark & \text { Jones paid for lunch } \\ \text { Subj } & x & \text { Jones order breakfast } \\ \text { V } & \nearrow & \text { Smith paid for breakfast } \\ \text { Subj+V } & x & \text { Jones paid for breakfast } \\ \text { VP } & \checkmark & \text { Smith paid for lunch } \\ \text { Obj } & \checkmark & \text { Smith ordered lunch } \\ \text { Sub+Obj } & \checkmark & \text { Jones ordered lunch }\end{array}$

Figure 2: Unalternatives calculated at the VP, (i), and S level, (ii); (iii) shows how the (weak) restriction introduced at the $\mathrm{S}$ level, and the weak restriction propagated from the VP level can be combined into a single restriction. The resulting predictions regarding what can and cannot be a focal target according to $Q^{\text {smith ordered }}$ breakfast are shown in the table in (iv). The leftmost column indicates what kind of focus this would correspond to in a system using F-marking. 
(6) PROPAGATION

any branching node $\left[\mathrm{S}_{1} \mathrm{~S}_{2}\right]$ excludes all focal targets in $\left(\operatorname{alt.dom}\left(S_{1}\right) \otimes_{\alpha} \llbracket \mathrm{S}_{2} \rrbracket_{u}\right)$ as well as those in $\left(\llbracket S_{1} \rrbracket_{u} \otimes_{\alpha}\right.$ alt.dom $\left.\left(S_{2}\right)\right)$

In most cases restrictions imposed by strong and weak restriction and by propagation can be combined into a single restriction, as in Figures 2 and 3.

The overall set of possible Focal Targets for the two structures in Figures 2 and 3 are summarized in the tables in Figure 2(iv) and Figure 4.

(i)

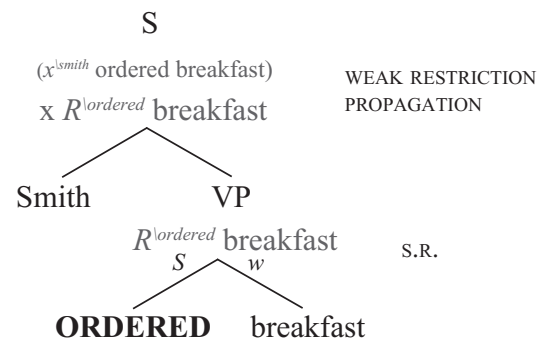

(ii)

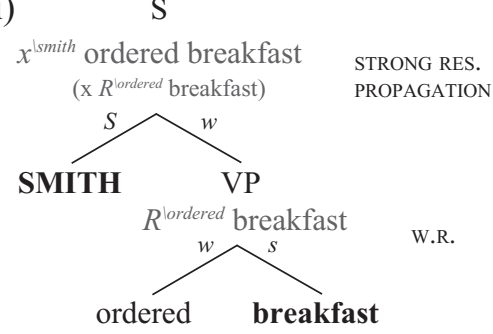

Figure 3: Strong restriction, applied at the VP- and S-levels (3(i)/3(ii), respectively); note that in the latter case, normal metrical weights, $w-S$, are assigned within the VP.

\begin{tabular}{|c|c|c|c|}
\hline \multicolumn{2}{|c|}{$\begin{array}{c}\text { Smith ORDERED breakfast } \\
\text { x R R } R^{\text {lordered }} \text { breakfast }\end{array}$} & \multicolumn{2}{|c|}{$\begin{array}{l}\text { SMITH ordered breakfast } \\
x^{\text {lsmith }} \text { ordered breakfast }\end{array}$} \\
\hline$S$ & $x$ Jones paid for lunch & $\mathrm{S}$ & $x$ \\
\hline Subj & $x$ Jones order breakfast & Subj & $\checkmark$ \\
\hline V & $\checkmark$ Smith paid for breakfast & V & $x$ \\
\hline Subj+V & $\checkmark \quad$ Jones paid for breakfast & Subj+V & $x$ \\
\hline VP & $x$ Smith paid for lunch & VP & $x$ \\
\hline Obj & $\boldsymbol{x}$ Smith ordered lunch & Obj & $x$ \\
\hline $\mathrm{Sub}+\mathrm{Obj}$ & $x$ Jones ordered lunch & $\mathrm{Sub}+\mathrm{Obj}$ & $x$ \\
\hline
\end{tabular}

Figure 4: Predictions for prosodic reversal at the VP and S level, respectively.

\subsection{Discontinuous Foci in Unalternative Semantics}

The tables in Figure 2(iv) and in Figure 4 each contain one licit discontinuous focus, $\mathrm{Subj}+\mathrm{Obj}$ and Subj $+\mathrm{V}$, respectively. The latter of these is the kind we looked at in section 1, transitive subject plus verb. This is illustrated in detail in Figure 5(i). Figure 5(ii) schematizes the configuration in which discontinuous foci can come about in Unalternative Semantics in general: whenever the strong daughter $\alpha$ of a branching node $\mu$ with 
default stress among its daughters, is itself branching; in that case $\alpha$ 's strong daughter, $C$, and its 'aunt', $A$ may be interpreted as a discontinuous focus.

(i)

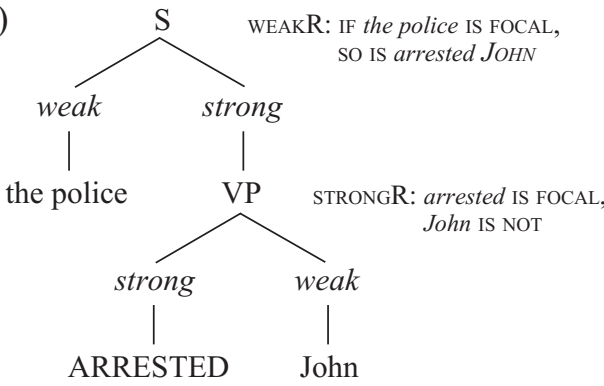

(ii)

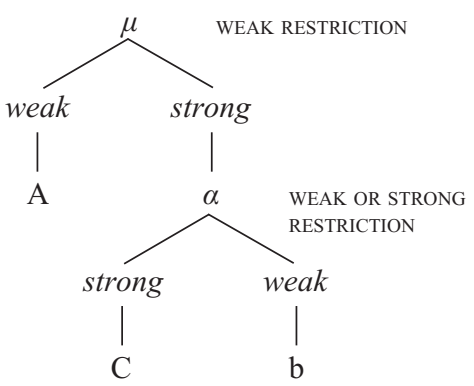

Figure 5: The restrictions imposed on 5(i), the tree corresponding to (1b), are compatible with the police arrested (but not John) being focal, so that 'what happened to John', or the meaning of any answer to it, is a possible Focal Target. Generally, UAS predicts that two constituents $\mathrm{A}+\mathrm{C}$ can be interpreted as a discontinuous focus in exactly two con gurations, those in 5(ii), with the order of sisters irrelevant. Note that if has default metrical weights (and hence Weak Restriction applies), the entire discontinuous focus structure will be realized by default stress.

\section{OTHER INSTANCES OF DISCONTINUOUS FOCI}

Using the standard question/answer test for pragmatically determining the focus in an answer, we can actually rather frequently diagnosed a discontinuous focus.

For example, (7a) shows a discontinuous focus consisting of a transitive verb and an indirect object to the exclusion of the direct object the books. Note that $(7 \mathrm{~b})$ actually displays the same kind of discontinuous focus, except that in this case no prosodic reversal (i.e., deaccenting) has taken place - so this case is less spectacular on the surface.

(7) What did you do with the books?

a) I sent $\mathrm{KIM}_{\mathrm{F}}$ the books.

b) I sent the books to KIM $_{\mathrm{F}}$.

As anticipated in the table in Figure (2iv), a discontinuous focus may also consist of the subject and the object of a transitive sentence, as in (8).

(8) (A lot of people were introduced to the mayor, but) no-one/nun introduced $\underline{\mathrm{SUE}}_{\mathrm{F}}$.

(8) is another case in which DF is realized by default prosody. We can, however, change it so as to make sure that indeed only the object, but not the verb, is part of the 
focus. The key to that is the first of the prosodic defaults in Figure 1: between a functional and a lexical sister, the lexical one is strong by default, regardless of linear order or other factors. This can be seen in the broad focus examples in (9).

(9) If Sue continues to work like this, John will

a) ... HIRE her/ introDUCE himself/ SAY something/ REPORT that.

b) ... hire HELP/ introduce new RULES/ say the TRUTH/ report the OPposite.

If we now embed a VP of this sort - strong verb, weak pronominal object - in a configuration like (8), we get a non-default stress pattern:

(10) (A lot of people were introduced to the mayor, but) no-one/nun introduced $\underline{\mathrm{ME}}_{\mathrm{F}}$.

The default pattern in this case would accent the verb instead, as in (11).

(11) (A lot of people were introduced to the mayor, but ...) no-one/nun TOLD me ${ }_{\mathrm{F}}$.

So we can indeed be sure that (10) is an instance of discontinuous focus, and, by parity of reasoning, (8) is, too. I will return to the significance of cases like these in section 4.2 .

Indeed, such discontinuous foci can even result in both 'extraordinary accenting' (of a pronoun) and deaccenting at the same time.

(12) (A lot of people were introduced to the mayor, but) no-one/nun introduced $\mathrm{ME}_{\mathrm{F}}$ to the mayor.

All of these examples also illustrate that prosodic reversal (i.e., non-default stress) is not the same deaccenting; prosodic reversal in (9a) and (10) manifests itself in the addition of a pitch accent on the functional object me, which would otherwise be unstressed. The same effects can be observed in (13), where an additional stress, which happens to end up being the nuclear stress of the sentence, is put on the verbal particle back (the normal intonation here would have the nuclear pitch accent on books).

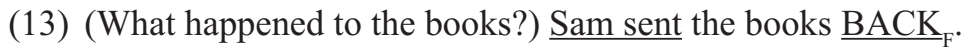

Accent addition as a result of prosodic reversal is also commonly found in head final verb phrases, where the second default from Table 1 - that a predicate is weak and its argument strong - applies. Dutch and German VPs provide a well-known case in question, as in example (14). Here too, neutral stress would fall on the object Bücher, rather than the sentence-final verb. Again prosodic reversal has taken place, resulting in an additional pitch accent on the structurally weak head-sister of the phrase. 
(14) Where are the books?

KIM hat die Bücher ABgeholt $_{\mathrm{F}}$.

$\mathrm{K}$. has the books up picked

'Kim picked the books up.'

I mention these different instances of discontinuous focus because they, collectively, pose severe difficulties for alternative representations, which I will discuss in the next section.

\section{A LOOK AT ALTERNATIVE ANALYTICAL OPTIONS}

In this section we will take a closer look at alternative analyses for the phenomenon of discontinuous focus. As said at the outset, it would seem that the two major analytic options are to analyze discontinuous focus as an instance of multiple focus, or as an instance of broad focus with focus-internal givenness deaccenting. We will inspect these options in turn.

\subsection{Discontinuous Focus vs. Double Focus}

(15a) illustrates what the initial example would be analyzed like using F-markers on the individual parts of the discontinuous focus (whereas (15b) indicates the kind of analysis advocated here, though recall that no actual syntactic marking of the focused constituents is part of the theory). Standard alternative semantics would actually assign the same set of focus alternatives to this structure that it would to an ordinary VP focus like the one in (1a).

(15) claim:

a) $*[\text { the police }]_{\mathrm{F}}[\text { arrested }]_{\mathrm{F}}$ John

b) the police arrested ${ }_{\mathrm{F}} \mathrm{John}$

So while semantically no argument against (15a) would be forthcoming, we may object to the predictions such an analysis would make regarding the prosodic realization of such examples. Notice that according to the F-marking pattern in (15), both the subject the police and the transitive verb arrested are foci in the sense of for example Selkirk (1995) (there called FOCus). That is to say, both are F-marked constituents which are not dominated by another F-marker.

One prediction of this representation is that both parts of the discontinuous focus should be realized as foci; in particular neither of them should be able to undergo phonological reduction. The examples in (16), however, clearly show that this prediction is not born out. The subjects in (16a) and (16b) may be reduced to the unstressed forms smon and $y a$. In (16c) it is even possible to drop the subject pronoun altogether.

(16) Where's Kim's homework?/What happened to Kim's homework?

a) Someone/Smone STOLE it. 
b) You're/Ya SITTING on it.

c) $I / \varnothing$ forgot it on the BUS.

Needless to say, none of this is expected if the subjects where themselves foci. ${ }^{1}$ This expectation is confirmed in the examples in (17) which are indeed double foci. In these cases reduction of the subject pronouns - either segmentally or by deletion - is completely impossible.

(17) a) (First, JO STOLE my homework and now) YOU are/*ya SITTING on it.

b) (First my brother misplaced my homework and now what happened?!) *(I) forgot it on the BUS.

A second argument in the same vein involves subject+transitive-verb foci which are realized by nuclear stress on the subject, as in (18a). However, this argument is currently more suggestive than decisive, since I do not fully understand the factors that lead to this configuration in the first place.

(18) John looks devastated. What happened to him?

a) Maybe his WIFE left him.

b) Maybe his WIFE died.

c) Maybe his DOG ran away.

If left in (18a) were itself a focus (not just part of one), it should not be able to remain unaccented. Standard cases in which focal predicates remain unaccented always involve them forming one larger focus with an argument, as would be the case if his wife left were a discontinuous focus in (18a). In that sense, (18a) is a problem for any analysis that assigns it the focus structure [his wife $]_{F}\left[[\text { left }]_{F}\right.$ him] .

In most cases discussed in the literature, this kind of INTEGRATION - realizing a broad $\mathrm{V}+$ argument focus with just one accent on the argument - involves internal arguments, including possibly unaccusative subjects as in (18b). Unergative intransitive subjects as in (18c) do partake in this pattern, too, as observed for example in Krifka (1984). Realizing a broad focus on a transitive subject, as in (18a), however, is generally thought to be impossible, and consequently excluded by standard algorithms for realizing focus, including the one assumed here. Evidently, this is in need of refinement: at least in some cases, including (18a), even transitive subjects may realize a broad focus, provided the internal argument can remain accent-less for independent

1 An anonymous reviewer suggests that, alternatively, 'weak pronouns, weak indefinites and the likes' should never be in the focus (so that (16) would be narrow V focus), or that, yet alternatively, the non-accenting of the subjects in (16) 'can be handled by the PF, through some kind of algorithm which reduces the prosodic shape in a particular set of cases' (hence suspending the assumption that a focus must contain an accent). Either move would require significant modifications to focus pragmatics and focus realization, respectively. Since I am not aware of any proposals with such features, I cannot pursue these lines of analysis further here. 
reasons, like him in (18a). ${ }^{2}$ Whatever the details, the accent pattern in (18a) is hard to reconcile with a representation that has both $\mathrm{V}$ and the subject be foci.

\subsection{Broad Focus with Anaphoric Deaccenting?}

Let us then turn to the second analytical possibility: could these examples be actually instances of broad, e.g., sentential, foci, within which anaphoric deaccenting has taken place?

The only standard test for teasing apart broad foci with deaccenting within them and narrower foci that I am aware of is ellipsis. Thus in (19), it is impossible to elide the verb phrase, even though will resign can be deaccented as given, and even though we know independently that bare subject answers are possible in English, if the subject is a narrow focus.

(E) (What will happen if Sam resigns?)

a) (Then) KIM will resign.

b) \#KIM.

(E') (Who will oversee the project if Sam resigns?)

a) (Then) KIM will oversee the project.

b) KIM.

Unfortunately the ellipsis test is, as far as I can see, not applicable for the cases of discontinuous focus we are interested in here. This is probably due to the fact that the remnant of ellipsis itself has to be a constituent, which would mean that omission of the background in a discontinuous focus structure is by definition impossible. What we need, then, is a new diagnostic for the difference between deaccenting within a focus and discontinuous focus. In what follows I will tentatively investigate two avenues towards probing this difference in sections 4.2.1 and 4.2.3.

\subsubsection{Pragmatic Contrast}

My first attempt at mounting argument against the broad-focus-plus-deaccenting analysis of discontinuous foci involves the size of the focus, as probed by pragmatic contrast,

2 As with intransitive subject integration, such cases characteristically involve Allerton and Cruttenden's (1979) verbs of appearance and disappearance, and 'verbs expressing misfortune' (ostensibly what we have in (18)). An anonymous reviewer suggests that the verbs in (18) are 'already implied by the ... subject' and hence not in need of focussing. However, as the reviewer themself points out, the fact that different predicates would have to be implied by the same subject in the same context in (a) vs. (b) casts doubt on such a story. It may also be of interest to note that a parallel context implicating fortunate events, rather than misfortune, does not seem to allow for integration in the same way:

(i) John looks happy. What happened?

a) Maybe his PARTNER wants to marry him.

b) \#Maybe his DAUGHTER graduated. 
as well as the focus sensitive particle also. What is crucial to the argument is the fact that deaccenting within a focus does not affect the focus alternatives generated by standard alternative semantics. For example, if the second clause in (19) were to be represented as in (20a), it should permit verb phrase focus alternatives, that is: properties.

(19) What did the guy who delivered the fridge do wrong? He scratched the EDges of the fridge.

(20) claim:

a) *he [scratched the EDges of [the fridge $\left.]_{\mathrm{G}}\right]_{\mathrm{F}}$.

b) he scratched the EDges of $f_{\mathrm{F}}$ the fridge.

According to the analysis advocated in the present paper, on the other hand, the structure is more akin to that in (20b), in which the noun phrase the fridge is not part of the focus and therefore not able to license focus alternatives. According to that analysis, only focal targets that describe relations between the delivery person and the fridge are permitted by (19).

This I attempt to put to the test in (21). We observe that (21a) sounds odd in the context given. This is expected if - as assumed here - the focus excludes (of) the fridge and thus the alternatives available to also are of the form 'they did $\mathrm{x}$ to the fridge', since the context specifies no other damage done to the fridge. In (21b), on the other hand, we clearly have VP focus, permitting alternatives 'they Q', so that 'they broke the glass door' can satisfy the presuppositions of also.

(21) So ok, the guys who delivered the fridge broke the French doors in the living room. What other damage did they do? ...

a) \#They also scratched the EDges of the fridge.

b) They also scratched the edges of the FRIDGE.

According to the 'broad-focus-plus-deaccenting' view, (21a) and (21b) have the exact same F-pattern (the sole difference being G-marking on the fridge) and focus alternatives, (22).

(22) a) they also [scratched the edges of [the fridge $\left.]_{(\mathrm{G})}\right]_{\mathrm{F}}$

b) 'they also Q'

So the felicity of also should be unaffected by whether or not fridge is deaccented. In fact, if anything, (21a) should be the preferred realization, given the generally held view that givenness marking should be maximized. ${ }^{3}$ This strongly suggests that the

3 E.g., 'Do Not Overlook Anaphoric Possibilities' in Williams (1997), or analogous principles that minimize focus marking, e.g., 'AvoidF' in Schwarzschild (1999), the requirement that given elements must at most be FOCus marked in Selkirk (1995), 'Maximize Presupposition' in Sauerland (2005), or 'Maximize Background' in Büring (2012). 
fridge is not part of the focus in (21a), i.e., that we are dealing with a discontinuous focus, scratched the edges of.

I used also in (21) to check the maximum size of a focus: the more focus alternatives are available, the more permissive (regarding possible antecedents) also should become. A parallel argument can be mounted using free focus. The contrast in (23) exactly parallels that in (21).

(23) So ok, the guys who delivered the fridge broke the French doors in the living room. What other damage did they do? ...

a) \#They scratched the EDges of the fridge.

b) They scratched the edges of the FRIDGE.

As before, if 'broke the French doors in the living room' were among the alternatives to scratched the EDGES of the fridge (in this context, that is, where fridge is given) (23a) should be as good as, if not better than, (23b). In contradistinction, the discontinuous focus analysis favored here again correctly predicts that only (23b) will be felicitous here, if 'broke the glass door' is to be the focal target.

These examples have implication beyond determining the size of the focus, which I will only touch upon here. They suggest that, in general, there is no such thing as pure givenness deaccenting within a broad focus; this implies in turn that, for example, the focal targets in (19) must be (other) 'things he did to the fridge', not 'things he did wrong' in general, even though that is not, strictly speaking, salient in the context. (21) and (23) furthermore indicate that 'deliver the fridge' is not an available focal target for scratch the EDGES of the fridge in these examples (otherwise (21a) and (23a) should be fine, as 'things they do with/to the fridge' are permitted alternatives, even under the discontinuous focus analysis); ostensibly this is because there is no pragmatic contrast between delivering the fridge and scratching its edges; a full account of focussing needs to model such a contrast requirement, which e.g., the proposals in Rooth (1992) and Schwarzschild (1999) do not (see Wagner 2006b, 2012 and Katzir 2013 for discussion, Büring (forthcoming) for a recent proposal utilizing Unalternative Semantics).

The basic contrast used to argue against the 'broad-focus-plus-deaccenting' analysis of discontinuous foci, however, is, I think, not affected by these considerations; the crucial fact is simply that these cases do not behave like VP- or sentential foci.

\subsubsection{Excursus: Broad Focus with Givenness Movement}

An anonymous reviewer drew my attention to an alternative version of the broad-focusplus-deaccenting analysis, on which the given/deaccented elements within the focus are moved out of the focus, either string vacuously, where applicable, or at 'Logical Form', as in (24) (thanks to the reviewer, who also suggested the structures on which those in (24) are based).

(24) a) John ${ }_{1}$ the police arrested $\left.t_{1}\right]_{F}$

b) $I_{2}\left[\right.$ the books $\left.{ }_{1}\left[t_{2} \operatorname{sent~Kim~} t_{1}\right]_{F}\right]$ 
Implementations of this idea are found for example in the detailed analysis of overt givenness movement in Czech in Kučerová (2007), and in Wagner's $(2005 ; 2010)$ analysis of deaccenting in coordination in English.

This alternative is worth considering, as it may be compatible with a focus semantics on which the alternatives derived in (24) are indeed of the kind 'John Q' and 'I did $\mathrm{Q}$ with the books', respectively; in that case, the arguments presented in 4.2.1 would not affect such an analysis. ${ }^{4}$

As far as I can tell, and as again anticipated by the reviewer, arguments against such an alternative analysis could only come from syntactic considerations. For example, such an analysis would require covert movement of a transitive verb in the case of (8)/ (11), sketched in (25a), and movement out of a complex NP in (19)/(21a), see (25b) (complex NP in boldface; thanks once more to the reviewer for pointing this out).

(25) a) introduced ${ }_{1}\left[\text { no-one } \mathrm{t}_{1} \text { Sue } / \mathrm{me}\right]_{\mathrm{F}}$

b) the fridge $e_{1}\left[\right.$ they/he (also) scratched [the edges of $\left.\left.t_{1}\right]\right]_{F}$

Interestingly, both Kučerová $(2007)$ and Wagner $(2005,2010)$ argue that (their versions of) givenness movement need to obey syntactic islands so as to derive crucial facts in Czech and English, respectively. Wagner (2006a) does not discuss givenness movement, but the argument for focus movement in English in that paper crucially relies on the assumption that a transitive verb needs to pied-pipe its complement when moving for focus reasons; by parity of reasoning, one might expect givenness movement in (25a) to behave likewise. So while covert givenness movement may in principle derive the correct meanings, its syntactic feasibility would have to be assessed in the context of a complete account of movement, at least of the information structure related kind, a task which is beyond the scope of this article.

\subsubsection{Reordering v. Stress-Shift in Czech}

For my second attempt at teasing apart discontinuous foci from broad foci with the accenting, I will try to isolate a case in which the two are prosodically or morphosyntactically realized in different ways.

Groeben et al. (to appear) report that narrow focus in Czech is alternatively realized by positioning the focus rightmost, or shifting stress leftward onto the (unmarked position of the) focus (see also Šimík and Wierzba 2015). The main stress is indicated by boldface, $\underline{\text { focus }}_{\mathrm{F}}$ by underlining, leftward moved material in gray type.

(26) Q: Přiměla Marie Václava k odchodu?

'Did Marie convince Václav to leave?'

mean rating

4 I am not aware of a version of focus semantics that would deliver these alternatives 'out of the box', but Krifka's (1993) analysis of foci with bound pronouns in them should serve as a good blueprint for a focus semantics that allows binding of traces within the focus (alternatives), as required here, see the summary discussion in (Büring 2016, sec.10.4.3). 
a) Marie přiměla $\mathrm{k}$ odchodu $\underline{\text { Jiř́ího }}_{\mathrm{F}}$.

M.NOM convinced to leaving J.ACC

'Marie convinced Jirí to leave.'

b) Marie přiměla $\underline{\text { Jiř́ho }}_{\mathrm{F}} \mathrm{k}$ odchodu.

The mean ratings of 7.9 and 7.3 do not, according to Groeben et al. (to appear) show a significant preference for either of these options. Stress-shift within a focus, on the other hand, is dispreferred; reordering is preferred instead.

(27) Q: Nevíš, jestli už všichni odešli?

mean rating

'Do you have an idea if everyone left yet?'

a) Marie primĕla $\mathrm{k}$ odchodu Jiřího. ${ }_{\mathrm{F}}$

M. NOM convinced to leavning J.ACC

'Marie convinced Jiří to leave.'

b) \#Marie priměla Jiř́ího k odchodu ${ }_{\mathrm{F}}$

Here the difference in mean acceptability ratings is significant: reordering is the preferred realization. We should now be able to use the different preference patterns to probe whether a given construction shows narrow, possibly discontinuous, focus, or broad focus with internal deaccenting. Groeben et al.'s (to appear) own data may actually provide a case in question: in certain conditions, the expected preference for reordering was not found, see (28).

(28) Q: Vyzvala Marie Jiř́ho k odchodu?

'Did Marie ask Jiří to leave?'

a) Marie Jiř́ho k odchodu přiměla. ${ }_{F}$ M.NOM J.ACC to leaving convinced 'Marie convinced Jiří to leave.'

b) Marie přiměla ${ }_{\mathrm{F}}$ Jiř́h $\mathrm{k}$ odchodu

mean rating

(29) Q: Nevíš, proč Jiř́i odešel?

'Do you have an idea why Jiř́ left?'

mean rating

a) Marie Jiř́ího k odchodu prriměla. ${ }_{\mathrm{F}}$

M.NOM J.ACC to leaving convinced

'Marie convinced Jiří to leave.'

b) Marie přimĕla Jiřího k odchodu. ${ }_{F}$

Groeben et al. (to appear) speculate that (28b) and (29b) may involve 'focus accommodation' (to a narrow V focus). But this may in fact be a case of discontinuous focus, which would explain the lack of an effect: (29) is an instance of 'moving background to the left of focus', as indicated in (30) (as before, keep in mind that the F-marking is for perspicuity only). 
(30) Q: Nevíš, proč Jiř́i odešel?

'Do you have an idea why Jir left?'

a) Marie Jiř́ho $\mathrm{k}$ odchodu přimĕla. ${ }_{\mathrm{F}}$ M.NOM J.ACC to leaving convinced

'Marie convinced Jiř́ to leave.'

b) Marie přimĕla ${ }_{\mathrm{F}}$ Jiř́ho k odchodu.

Note that this argument hinges on the premise that in Czech, both discontinuous focus and focus-internal deaccenting, are possible - possibly unlike in English, if our remarks in the previous subsection were on the right track. I will leave it for future work to explore these differences in more depth.

\section{SUMMARY}

In this paper I have demonstrated how Unalternative Semantics provides a natural way to model discontinuous foci. Several cases from English were discussed which should plausibly be analyzed as such. Crucially, since Unalternative Semantics does not use syntactic F-markers to represent focus, the questions whether 'the' focus is a constituent, as well as whether a discontinuous focus is the same as multiple foci, cannot even arise. ${ }^{5}$ As discussed above, either way of answering it in a framework that uses F-marking leads to problematic consequences for either focus realization or interpretation, indirectly arguing the case for the type of treatment advocated here.

\section{References}

ALLERTON, D.J./A. CRUTTENDEN (1979) "Three Reasons for Accenting a Definite Subject." Journal of Linguistics 15/1, 49-53.

BÜRING, Daniel (2012) "What's New (and What's Given) in the Theory of Focus?" In: Sarah Berson/Alex Bratkievich/Daniel Bruhn/Ramon Escamilla/Amy Campbell/Allegra Giovine/Lindsey Newbold/ Marta Piqueras-Brunet/Marilola Perez/ Russell Rhomieux (eds), Proceedings of the Thirty-Fourth Annual Meeting of the Berkeley Linguistics Society, February 8-10 2008. Berkeley, CA: Berkeley Linguistics Society, 403-424.

BÜRING, Daniel (2015) “Unalternative Semantics.” In: Sarah D’Antonio/Mary Moroney/Carol Rose Little (eds), Proceedings of SALT 25. Washington: Linguistic Society of America, 550-575.

BÜRING, Daniel (2016) Intonation and Meaning. Surveys in Semantics and Pragmatics. Oxford: Oxford University Press.

5 I do think that, alongside the discontinuous focus pattern discussed here, a true double focus pattern exists, which, among other things, realizes both foci as intermediate phrase heads, and thus prohibits prosodic reduction of both focused elements. A tentative analysis for these cases is offered in Büring (forthcoming). 
BÜRING, Daniel (forthcoming) "Focus, Questions and Givenness." In: Klaus von Heusinger/Edgar Onea/Malte Zimmermann (eds), Questions in Discourse. Holland: Brill.

GROEBEN, Lena/Radek ŠIMÍK/Frank KÜGLER (to appear) "Stress Shift, Focus, and Givenness in Czech." In: Proceedings of Formal Approaches to Slavic Linguistics (FASL) 24. Michigan Slavic Publications.

KATZIR, Roni (2013) “A Note on Contrast.” Natural Language Semantics 21/4, 333-343.

KRIFKA, Manfred (1984) Fokus, Topik, syntaktische Struktur und semantische Interpretation. Available: http://amor.cms.hu-berlin.de/ h2816i3x/Publications/Krifka\%201984\%20Fokus.PDF.

KRIFKA, Manfred (1993) "Focus and Presupposition in Dynamic Interpretation." Journal of Semantics 10, 269-300.

KUČEROVÁ, Ivona (2007) The Syntax of Givenness. PhD dissertation. MIT.

ROOTH, Mats (1985) Association with Focus. PhD dissertation. UMass Amherst.

ROOTH, Mats (1992) “A Theory of Focus Interpretation." Natural Language Semantics $1,75-116$.

ROOTH, Mats (1996) "Focus." In: Shalom Lappin (ed.), The Handbook of Contemporary Semantic Theory. London: Blackwell, 271-297.

SAUERLAND, Uli (2005) “Don't interpret focus: Why a presuppositional account of focus fails, and how a presuppositional account of givenness works." In: Proceedings of Sinn und Bedeutung 9. Nijmegen, 370-384.

SCHWARZSCHILD, Roger (1999) "GIVENness, AvoidF and Other Constraints on the Placement of Accent." Natural Language Semantics 7/2, 141-177.

SELKIRK, Elisabeth (1995) "Sentence Prosody: Intonation, Stress, and Phrasing." In: John A. Goldsmith (ed.), The Handbook of Phonological Theory. London: Blackwell, 550-569.

ŠIMÍK, Radek/Marta WIERZBA (2015) "The Role of Givenness, Presupposition, and Prosody in Czech Word Order: An Experimental Study." Semantics and Pragmatics 8/3,1-103.

WAGNER, Michael (2005) Prosody and Recursion. PhD disseertation, MIT.

WAGNER, Michael (2006a) "Association by movement: evidence from NPI-licensing." Natural Language Semantics 14/4, 297-324.

WAGNER, Michael (2006b) "Givenness and Locality." Semantics and Linguistic Theory (SALT) 16, 295-312.

WAGNER, Michael (2010) "Prosody and Recursion in Coordinate Structures and Beyond." Natural Language and Linguistic Theory 28, 183-237.

WAGNER, Michael (2012) "Focus and Givenness: A Unified Approach." In: Ivona Kučerová/Ad Neeleman (eds), Contrasts and Positions in Information Structure. Cambridge: Cambridge University Press, 102-147.

WILLIAMS, Edwin (1997) “Blocking and Anaphora.” Linguistics Inquiry 28, 577-628. 


\section{Summary \\ DISCONTINUOUS FOCI AND UNALTERNATIVE SEMANTICS}

Discontinuous foci - cases in which the focus as expected by semantic or pragmatic considerations is not a single constituent within the phrase marker - are not commonly discussed in the formal literature on focussing. This paper proposes to use Unalternative Semantics to analyze such foci. Unalternative Semantics is a novel framework for calculating focus alternatives from metrically annotated trees (instead of trees with Fmakers); this format naturally lends itself to the modelling of discontinuous foci. The paper compares this approach to other, alternative options involving F-markers and argues in favor of the F-less treatment.

Keywords: focus, discontinuous focus, alternative semantics, deaccenting, givenness

\section{Povzetek \\ PREKINJENI FOKUSI IN NEALTERNATIVNA SEMANTIKA}

Prekinjeni fokusi - primeri, v katerih fokus, določen glede na semantične in pragmatične značilnosti, ni enoten sestavnik - so v literaturi o fokusu redkeje obravnavani. Pričujoči članek pokaže razčlembo takšnih zgradb s pomočjo nealternativne semantike. Nealternativna semantika je novejši okvir, s katerim preračunavamo fokusne alternative iz metrično označenih dreves (namesto iz dreves označenih s F-oznakami); takšen pristop je posebej primeren za modeliranje prekinjenih fokusov. Članek primerja ta pristop z drugimi, alternativnimi možnostmi, ki vključujejo F-oznake, in zagovarja razčlembo brez takšnih oznak.

Keywords: fokus, prekinjeni fokus, alternativna semantika, nenaglašenost, danost 